\title{
EVALUATION OF ANTIDIARRHEAL ACTIVITY OF ETHANOLIC LEAF EXTRACT OF ERIOBOTRYA JAPONICA LINDL
}

\author{
DAVIE JUWA KAMADYAAPA ${ }^{1 *}$, MAVUTO MASOPERA GONDWE ${ }^{1}$, MATHULO SHAULI ${ }^{1}$, \\ CONSTANCE SEWANI-RUSIKE ${ }^{1}$, JEHU IPUTO²
}

\begin{abstract}
${ }^{1}$ Department of Human Biology, Faculty of Health Sciences, Walter Sisulu University, Private Bag X1, Mthatha 5117, Republic of South Africa. ${ }^{2}$ Department of Medical Education, Faculty of Health Sciences, Walter Sisulu University, Private Bag X1, Mthatha 5117, Republic of South Africa. Email: dkamadyaapa@yahoo.co.uk
\end{abstract}

Recevied: 15 May 2018, Revised and Accepted: 10 August 2018

ABSTRACT

Objective: The study was carried out to investigate the antidiarrheal activity of ethanolic leaf extract of Eriobotrya japonica (EEJ) using various models of experimental diarrhea.

Methods: Antidiarrheal property of EEJ at 100, 200, and $400 \mathrm{mg} / \mathrm{kg} /$ bwt was evaluated using castor oil-induced diarrhea, castor oil-induced enteropooling, and gastrointestinal propulsive models of experimental diarrhea in Sprague Dawley rats of both sexes, weighing $200-250$ g. Cytotoxicity test of EEJ was performed using brine shrimp bioassay.

Results: Toxicity assay of EEJ showed a lethal concentration value of $1225 \mu \mathrm{g} / \mathrm{ml}$ suggesting non-toxicity. EEJ significantly (p<0.05) and dose-dependently (100, 200 and $400 \mathrm{mg} / \mathrm{kg} /$ bwt) inhibited castor oil-induced diarrhea by 38.1\%, 76.19\%, and 100\%, respectively, and enteropooling by $28 \%, 56 \%$, and $88 \%$, respectively, compared with control. Pre-treatment with yohimbine, $\alpha 2$-adrenoceptor blocker significantly reversed the protective effect of EEJ ( $400 \mathrm{mg} / \mathrm{kg}$ ) against castor oil-induced diarrhea and against castor oil-induced enteropooling, suggesting the involvement of $\alpha 2$-adrenoceptors in antidiarrheal property of EEJ. Furthermore, EEJ significantly $(\mathrm{p}<0.05)$ and dosedependently $(100,200$, and $400 \mathrm{mg} / \mathrm{Kg} / \mathrm{bwt})$ inhibited gastrointestinal motility by $28 \%, 62 \%$, and $83.92 \%$, respectively.

Conclusion: The study has demonstrated the antidiarrheal potential of ethanolic leaf extract of EEJ, which may be attributable to its dual antisecretory and antimotility activities probably through activation of the sympathetic $\alpha 2$-adrenergic pathway.

Keywords: Eriobotrya japonica, Enteropooling, $\alpha 2$-adrenoceptors, Cytotoxicity, Anti-secretory.

(C) 2018 The Authors. Published by Innovare Academic Sciences Pvt Ltd. This is an open access article under the CC BY license (http://creativecommons. org/licenses/by/4. 0/) DOI: http://dx.doi.org/10.22159/ajpcr.2018.v11i9.27256

\section{INTRODUCTION}

Diarrhea is a common gastrointestinal disorder affecting people of all ages worldwide. Diarrhea is usually characterized by the passage of a large volume of loose or watery stool at an increased frequency usually 3-4 times a day or stool volume $>200 \mathrm{ml} /$ day irrespective of the cause, be it infectious or not [1-3]. Diarrhea results from an imbalance between absorption and secretory processes that occur in the intestinal mucosa, and it is associated with excessive loss of essential electrolytes such as sodium ions, potassium ions, and chloride ions leading to dehydration and electrolyte imbalances [4,5]. Diarrheal diseases are usually associated with low living standards, poor sanitation infrastructure and poor access to portable, and safe-treated water sources [6,7]. Many rural dwellers depend mostly on the pond and river waters, whereby the community members share with household animals $[8,9]$. Reports suggest that about 2.4 billion people do not have basic sanitation with 1.1 billion people lacking access to improved and treated water supply worldwide [10]. South Africa is commended for achieving the water and sanitation targets for the millennium development goal with over $90 \%$ of South Africans having access to clean public water. However, estimates indicate that there are 6 million households and 1.4 million households which still lack access to clean water and sanitation services, respectively [11], putting this group of people at risk of getting diarrheal diseases.

Diarrhea leads to death if dehydration and electrolyte loss persist and become too severe without rehydration or treatment $[12,13]$. Worldwide, diarrhea claims several million lives annually and is reportedly to be the second leading cause of deaths mostly those of infants [14]. For instance, global mortality estimate from diarrhea is reported to be over 1.5 million deaths of children under the age of five annually [15]. In 1998, a estimated number of people killed by diarrhea worldwide were 7.1 [16]. The prevalence and incidences of diarrhea are on the rise especially in developing nations including South Africa. For instance, every year, South Africa reports about 3 million incidents of diarrheal cases requiring treatment. Furthermore, in South Africa alone, every year, and diarrheal diseases are claimed to be responsible for about 43000 deaths, with under five deaths accounting for $20 \%$ [17].

Diarrhea is treated with a number of available conventional drugs the most efficacious of which is loperamide, which acts both as antisecretory and antimotility drug in the intestines [18]. However, use of these conventional drugs has some limitations as some present with undesirable effects such as vomiting, fever, constipation, bronchospasms, dry mouth, and abdominal pains among others [19] and in addition, most infectious diarrhea are treated with a course of antibiotics, which currently is faced with massive drug-resistant challenges [20,21]. Furthermore, they are expensive and not easily accessible to ordinary poor rural communities. In most cases, they are not even available due to lack of adequate health facilities such as clinics and hospitals that are located at a very far distance from the community members [22]. It is because of these limitations that people resort to use of herbal remedies and other alternative treatments which have been perceived to be effective, affordable, and accessible and indeed with fewer or no side effects.

Worldwide, about $80 \%$ of communities rely on herbal remedies to treat various human ailments including diarrhea and other gastrointestinal 
disorders [23]. Moreover, the WHO has encouraged the use of traditional medicinal plants for the treatment and prevention of diarrhea worldwide [24,25]. A number of medicinal plants have been evaluated for their antidiarrheal properties, and reports indicate that they possess antispasmodic activities, delay gastrointestinal transit, inhibit motility of the gut, and reduce the intraluminal fluid accumulation with a concomitant enhancement of water and ion absorption [26,27]. Eriobotrya japonica (EEJ) Lindl. commonly known as loquat tree is one of such plants which is popularly and commonly used in the traditional medicine practice by several communities in treating various human diseases including diarrhea and other gastrointestinal-associated disorders by many rural communities of South Africa, especially in the Eastern Cape Province. Several biological activities of this plant have been reported. For instance, extracts obtained from this plant are reported to possess anti-inflammatory, antidiabetic, antioxidant, antiallergy, hyperleptinemia, hyperinsulinemia, and several other disorders [28-32]. Despite its long traditional use in the treatment of diarrhea, there is little documented scientific information regarding its antidiarrheal properties. The present study, was, therefore, conducted to scientifically evaluate the antidiarrheal effect of ethanolic leaf extract of EEJ using various models of diarrhea in an attempt to establish its efficacy and possible mechanism(s) of actions.

\section{METHODS}

\section{Plant material}

Leafy parts of EEJ were collected from areas surrounding Walter Sisulu University, Mthatha Campus. Identification and authentication of the plant were done by a senior taxonomist of the herbarium section, Department of Biological Sciences Walter Sisulu University, Mthatha Campus. A herbarium specimen was prepared and deposited with a voucher number: Nomathithi 1 (KEI).

\section{Preparation of ethanolic leaf extract of EEJ}

The leaves were shredded and allowed to air-dry under shade at room temperature for $3 \mathrm{w}$. The dried leaves were then milled into powder using a commercial blender. The powdered material was soaked in $70 \%$ ethanol and allowed to stay for $2 \mathrm{~d}$ with continuous shaking using (Labcon) platform shaker machine at room temperature. The resultant mixture was filtered using Whatman No. 1 filter paper in Buchner funnel. The filtrate was concentrated using the rotary evaporator under reduced pressure at $55^{\circ} \mathrm{C}$. The semi-solid concentrated extract was finally dried in an oven at $40^{\circ} \mathrm{C}$ to obtain a crude extract which was designated EEJ and was kept in a bio-freezer at $-75^{\circ} \mathrm{Cuntil}$ the day of experiments.

\section{Animals}

Sprague Dawley rats of both sexes, weighing 200-250 g were used for the study. Rats were supplied by Shalom Laboratories and housed in the storage facility in the Department of Physiology, Walter Sisulu University. The animals were kept in polypropylene open top cages (four in each cage) and were maintained at an ambient temperature of $25 \pm$ $2^{\circ} \mathrm{C}$ and $12 \mathrm{~h}$ light/12 $\mathrm{h}$ dark regime. The animals were acclimatized to the animal housing storage unit and laboratory conditions for $2 \mathrm{w}$ before the commencement of the experiment and during this period animals were fed with standard rat pellet chow (Epol SA) and water ad libitum. The experimental protocol and all procedures were approved by the Faculty of Health Sciences Research Ethics Committee, Walter Sisulu University. Animals were handled in compliance with the Guide for care and use of Laboratory Animals (NIP Publication No. 85 (23), revised in 1996).

\section{Experimental design}

The cytotoxicity test of the extract was performed using Brine Shrimp lethality bioassay. To establish the antidiarrheal activity of EEJ, the extract was screened against various models of diarrhea, namely castor oil-induced diarrhea, castor oil-induced enteropooling, and castor oilinduced gastrointestinal propulsion in rats. Before commencement of the experiments, the rats were fasted either for 18 or $24 \mathrm{~h}$ depending on the experimental procedure. Administration of the extract and loperamide was performed by intragastric gavage using straight feeding needles suitable for the animal depending on its size, whereas yohimbine and atropine were administered intraperitoneally (i.p) in live animals.

\section{Determination of cytotoxicity of EEJ}

The cytotoxic effect of EEJ was carried out using Brine shrimp lethality bioassay according to the model described by Nguta et al. [33], with slight modification. Brine shrimps (Artemia salina) were hatched using brine shrimp eggs in a rectangular vessel, containing $2 \mathrm{~L}$ of sterile artificial seawater (prepared using $\mathrm{NaCl} 38 \mathrm{~g} / \mathrm{L}$ ) under constant aeration for $48 \mathrm{~h}$, with artificial light shone on the opposite side of the rectangular hatchery. After hatching was achieved, active nauplii were collected from the brighter side of the hatchery and used for the assay. 10 nauplii were drawn through a glass capillary and placed into vials containing $4 \mathrm{ml}$ of brine solution for the control, and for the experimental groups, 10 nauplii were placed in $4 \mathrm{ml}$ of brine solution. The vial for the control group contained brine solution only, whereas the vials for experimental groups contained brine solution and EEJ of various concentrations $(1000 \mu \mathrm{g} / \mathrm{ml}, 500 \mu \mathrm{g} / \mathrm{ml}, 250 \mu \mathrm{g} / \mathrm{ml}, 125 \mu \mathrm{g} / \mathrm{ml}$, $62.5 \mu \mathrm{g} / \mathrm{ml}$, and $31.25 \mu \mathrm{g} / \mathrm{ml}$ ) with 3 duplicates per concentration. The mixtures were maintained at room temperature under constant light, and a $24 \mathrm{~h}$ survival larvae count was recorded. The mortality rate was determined as follows:

$\%$ deaths $=[($ Total nauplii-Alive nauplii $) /$ Total nauplii $] \times 100 \%$

\section{Lethal concentration $\left(\mathrm{LC}_{50}\right)$ determination}

The median $\mathrm{LC}_{50}$ in $\mu \mathrm{g} / \mathrm{ml}, 95 \%$ confidence interval and slope was determined after the $24 \mathrm{~h}$ count using the probit statistical analysis method [34]. LC $_{50}$ value of $>1000 \mu \mathrm{g} / \mathrm{ml}$ is considered non-toxic, LC $_{50}$ value $\geq 500 \mu \mathrm{g} / \mathrm{ml}$ and $\leq 1000 \mu \mathrm{g} / \mathrm{ml}$ is considered weak toxic, and $\mathrm{LC}_{50}$ value $<500 \mu \mathrm{g} / \mathrm{ml}$ is considered toxic [35].

\section{Effect of EEJ on castor oil-induced diarrhea in rats}

The antidiarrheal property of EEJ against castor oil-induced diarrhea was performed using a method described by Zavala-Mendoza et al. [36] with slight modifications. In brief, the rats were fasted for 18 hours before the commencement of the experiment with free access to water. A total number of 42 rats were randomly allocated into 7 groups with 6 rats per group as follows:

Group I was administered with normal saline (2 $\mathrm{ml} / \mathrm{Kg} / \mathrm{bwt})$ and acted as a negative control group. Groups II, III, and IV were administered 100, 200, and $400 \mathrm{mg} / \mathrm{kg} /$ bwt of EEJ, respectively. Group V was administered loperamide, a standard antidiarrheal drug at a dose of $5 \mathrm{mg} / \mathrm{kg} / \mathrm{bwt}$ and acted as a positive control. In a separate experiment, rats in Groups VI and VII were pre-treated with yohimbine ( $1 \mathrm{mg} / \mathrm{kg} / \mathrm{bwt}$ ) a selective $\alpha 2$ adrenergic receptor blocker and prazosin $(1 \mathrm{mg} / \mathrm{kg} / \mathrm{bwt}$.), a selective $\alpha 1$ adrenergic receptor blocker respectively, $30 \mathrm{~min}$ before the dose of $400 \mathrm{mg} / \mathrm{kg}$ of EEJ was administered. After $1 \mathrm{~h}$ of various doses of EEJ and loperamide administration, $2 \mathrm{ml} / \mathrm{kg} / \mathrm{bwt}$ of castor oil was administered orally to each rat to induce diarrhea. The animals were placed in individual cages lined with adsorbent papers. The cages were then observed for $4 \mathrm{~h}$ for the presence of characteristic diarrheal droppings. Time for the onset of diarrhea, total number of wet droppings and semisolid droppings was recorded for each cage during the $4 \mathrm{~h}$ period of observation. The time for onset was measured as the time interval between the administration of castor oil and the first appearance of wet droppings in minutes. The absence of wet droppings was considered as protection from diarrhea, and the percentage protection was calculated according to the formula described by Umukoro and Ashorobi [37] as follows:

\section{$[(\mathrm{NWDC}-\mathrm{NWDT}) / \mathrm{NWDC}] \times 100$}

Where NWDC=Number of wet droppings in control group and NWDT=Number of wet droppings in treatment groups. 
Effect of EEJ on gastrointestinal propulsion in rats

The effect of EEJ on gastrointestinal transit (motility) was investigated in rats using a method described by Marona and Lucchesi [38] with a slight modification. In brief, the rats were fasted for $24 \mathrm{~h}$ before the commencement of the experiment with free access to water. 36 rats were randomly allocated into 6 groups with 6 rats per group as follows:

Group I was given $2 \mathrm{ml} / \mathrm{kg} / \mathrm{bwt}$ of normal saline and acted as a negative control group. Groups II, III, and IV were administered 100, 200, and $400 \mathrm{mg} / \mathrm{kg} / \mathrm{bwt}$ of EEJ, respectively. To check whether EEJ has antimotility activity comparable to drugs with known antigastrointestinal motility, rats in Group V were given atropine sulfate $(0.3 \mathrm{mg} / \mathrm{kg} / \mathrm{bwt}$ i.p) muscarinic receptor antagonist. In a separate experiment, rats in Group VI were pre-treated with yohimbine $(1 \mathrm{mg} / \mathrm{kg} / \mathrm{bwt}$ i.p) a selective $\alpha 2$ adrenergic receptor blocker, $30 \mathrm{~min}$ before the dose of $400 \mathrm{mg} / \mathrm{kg}$ of EEJ was administered. After $1 \mathrm{~h}$ of administration of the normal saline, different doses of EEJ and atropine sulfate, each animal was given $2 \mathrm{ml}$ of the standard charcoal meal (10\% activated charcoal suspension in $2 \%$ tween 80 ) and $1 \mathrm{ml}$ of castor oil. After 1 hour of charcoal meal administration, each rat was sacrificed by cervical dislocation, and its abdomen was opened by midline incision. The small intestine was immediately isolated. The total length of the intestine from pylorus to caecum (total length of small intestine) and the distance traveled by the charcoal (length traveled by charcoal meal) were measured using a ruler in centimeters $(\mathrm{cm})$. The peristaltic index (PI) for each rat was calculated and expressed as a percentage $(\%)$ of the distance traveled by the charcoal meal relative to the total length of the small intestine. The PI and percent inhibition relative to control were calculated according to Degu et al. [39] as follows:

\section{$\mathrm{PI}=[\mathrm{LCM} / \mathrm{LSI}] \times 100 \%$}

Where: PI=Peristaltic Index

LCM=Length traveled by charcoal meal; LSI=Total length of small intestine

$\%$ Inhibition $=[(\mathrm{A}-\mathrm{T}) / \mathrm{A}] \times 100$

Where A=Distance traveled by charcoal meal in control group and $\mathrm{T}=$ Distance traveled by charcoal meal in treated groups.

Effect of EEJ on castor oil-induced enteropooling

The rats were fasted for $24 \mathrm{~h}$ before the commencement of the experiment with free access to water. 42 rats were randomly allocated into 7 groups with 6 rats per group as follows:
Group I was administered with $2 \mathrm{ml} / \mathrm{kg} / \mathrm{bwt}$ of normal saline and acted as a negative control. Groups II, III, and IV were administered 100, 200, and $400 \mathrm{mg} / \mathrm{kg} / \mathrm{bwt}$ of EEJ, respectively. Group V was administered loperamide, a standard antidiarrheal drug at a dose of $5 \mathrm{mg} / \mathrm{kg} / \mathrm{bwt}$ and acted as a positive control. In a separate experiment, rats in Groups VI and VII were pre-treated with yohimbine $(1 \mathrm{mg} / \mathrm{kg} / \mathrm{bwt} \mathrm{i} . \mathrm{p})$ a selective $\alpha 2$ adrenergic receptor blocker and prazosin (1 mg/kg/bwt i.p), a selective $\alpha 1$ adrenergic receptor blocker, respectively, $30 \mathrm{~min}$ before the dose of $400 \mathrm{mg} / \mathrm{kg}$ of EEJ was administered. After $1 \mathrm{~h}$ rats in each group were orally administered $2 \mathrm{ml} / \mathrm{kg} /$ bwt of castor oil. $30 \mathrm{~min}$ later, each rat was sacrificed by cervical dislocation, and its abdomen was opened by midline incision, and small intestine was ligated at both the pyloric and the ileocaecal junctions before it was isolated and weighed. The intestinal contents were squeezed and emptied into the graduated measuring cylinder, and the volume of contents was recorded. The intestine was reweighed without the intestinal contents, and the difference between the full and empty intestines was calculated, and percent inhibition was determined.

\section{Statistical analysis}

GraphPad Prism software was used for all analysis. The data were presented as means plus or minus standard errors of the means (SEM). One-way analysis of variance (ANOVA) followed by Tukey multiple comparison tests was employed to compare the treatment means with control means. Student's unpaired t-test was used to compare individual means for differences. $\mathrm{p}<0.05$ was considered statistically significant.

\section{RESULTS}

\section{Cytotoxicity of EEJ}

The median $\mathrm{LC}_{50}$ after the $24 \mathrm{~h}$ count using the probit statistical analysis method was found to be $1225 \mu \mathrm{g} / \mathrm{ml}$ and was considered non-toxic since it is $>1000 \mu \mathrm{g} / \mathrm{ml}$.

\section{Effect of EEJ on castor-oil induced diarrhea}

Oral administration of $2 \mathrm{ml}$ of castor oil produced marked copious diarrhea in all rats in the vehicle-treated control group during the $4 \mathrm{~h}$ period of observation. Fig. 1a and b shows that oral administration of EEJ significantly $(p<0.05)$ and dosedependently reduced the number of wet feces induced by castor oil, with groups of 100, 200, and $400 \mathrm{mg} / \mathrm{Kg} / \mathrm{bwt}$ producing 13,5 , and 0 number of wet feces, respectively, as compared with negative control group with 21 wet feces, after a $4 \mathrm{~h}$ period. A dose of $400 \mathrm{mg} / \mathrm{Kg} / \mathrm{bwt}$ and loperamide ( $5 \mathrm{mg} / \mathrm{Kg} / \mathrm{bwt}$ )

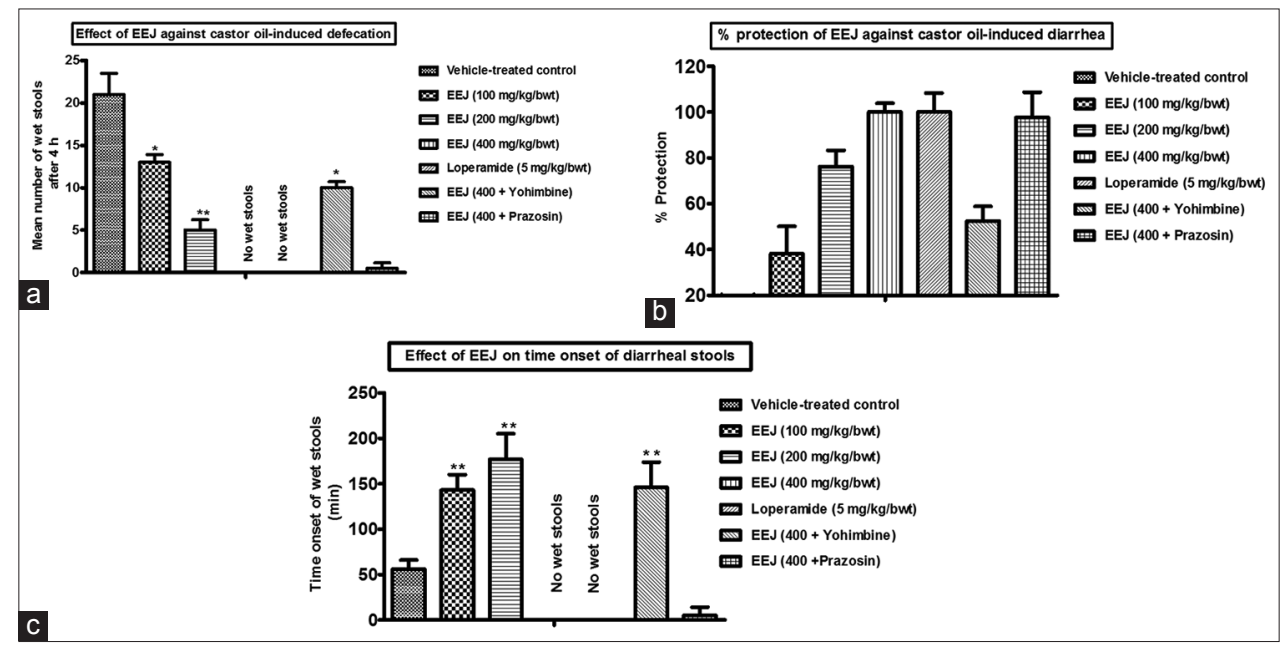

Fig. 1: (a) The effect of oral administration of Eriobotrya japonica (EEJ) against castor oil-induced diarrhea. Values are presented as means \pm standard errors of the means (SEM) $(n=6) .{ }^{*} p<0.05 ;{ }^{* *} p<0.01$ significantly different compared with negative control group. (b) The percent protective effect of oral administration EEJ against castor oil-induced diarrhea. Values are presented as means \pm SEM ( $n=6)$. (c) The effect of oral administration of EEJ on the time of onset of castor oil-induced diarrhea. Values are presented as means \pm SEM $(n=6)$. ${ }^{* *} p<0.01$ significantly different compared with negative control group 
caused complete inhibition of defecation, suggesting 100\% protection, whereas EEJ at $100 \mathrm{mg} / \mathrm{kg}$ and $200 \mathrm{mg} / \mathrm{kg}$ offered $38.1 \%$ and $76.19 \%$ protection, respectively, against castor oil-induced diarrhea. Pretreatment with yohimbine significantly reversed the protective effect of EEJ ( $400 \mathrm{mg} / \mathrm{kg}$ ) against castor oil-induced diarrhea $(52.38 \%$ vs. $100 \%$ when EEJ [400 mg/kg] was administered alone). Pre-treatment with prazosin did not significantly mitigate the protective effect of EEJ (400 mg/kg) against castor oil-induced diarrhea (97.62\% vs. 100\%) when EEJ ( $400 \mathrm{mg} / \mathrm{kg}$ ) was administered alone. Fig. 1c, on the other hand, shows that EEJ at $100 \mathrm{mg} / \mathrm{kg}$ and $200 \mathrm{mg} / \mathrm{kg}$ significantly delayed the time of onset of wet feces $(143 \pm 17$ and $177 \pm 28 \mathrm{~min}$. respectively. as compared with vehicle-treated control, $56 \pm 10 \mathrm{~min}$ ). The presence of yohimbine caused the onset of wet feces in EEJ $(400 \mathrm{mg} / \mathrm{kg})$ treated group at the $146^{\text {th }} \mathrm{min}$.

Effect of EEJ on castor oil-induced gastrointestinal enteropooling Table 1 shows the effect of oral administration of EEJ on castor oil-induced intestinal fluid accumulation. Oral administration of EEJ significantly $(\mathrm{p}<0.05)$ and dosedependently $(100,200$, and $400 \mathrm{mg} / \mathrm{kg} / \mathrm{bwt})$ reduced the volume of intestinal contents with percent inhibition of $24.37 \%$, $43.29 \%$, and $79.83 \%$, respectively, compared with the negative control group. The effect of EEJ ( $400 \mathrm{mg} / \mathrm{kg}$ ) was comparable to loperamide (77.37\%). The effect of EEJ at $400 \mathrm{mg} / \mathrm{kg} / \mathrm{bwt}$ was significantly reversed in the presence of yohimbine $(45.8 \%$ vs. $79.83 \%$ when EEJ [400 mg/kg]) was administered alone. Similarly, EEJ significantly and dosedependently $(100,200$, and $400 \mathrm{mg} / \mathrm{kg} / \mathrm{bwt})$ reduced the weight of intestinal contents with percent inhibition of $26.82 \%, 45.8 \%$, and $78.41 \%$, respectively, compared with the negative control group. The effect of EEJ ( $400 \mathrm{mg} / \mathrm{kg}$ ) was comparable to loperamide $(74.57 \%$ ). The effect of EEJ at $400 \mathrm{mg} / \mathrm{kg} / \mathrm{bwt}$ was significantly reversed in the presence of yohimbine ( $44.84 \%$ vs. $78.41 \%$ when EEJ [ $400 \mathrm{mg} / \mathrm{kg}]$ ) was administered alone. The effect of EEJ at $400 \mathrm{mg} / \mathrm{kg} / \mathrm{bwt}$ was not antagonized by prazosin.

\section{Effect of EEJ on castor oil-induced gastrointestinal propulsion}

Fig. 2a shows that oral administration of EEJ significantly $(p<0.05)$ and dosedependently $(100,200$, and $400 \mathrm{mg} / \mathrm{kg} / \mathrm{bwt})$ delayed the intestinal transit time of charcoal meal with PI of 61,38.04, and 15.55, representing percent gastrointestinal motility reductions of $28 \%, 62 \%$, and $83.92 \%$, respectively (Fig. 2b), as compared with the negative control group with PI of 94.55 . The effect of atropine at $0.3 \mathrm{mg} / \mathrm{kg} / \mathrm{bwt}$ was more pronounced than that of EEJ at $400 \mathrm{mg} / \mathrm{kg} / \mathrm{bwt}$ (95.92\% vs. 83.92\%), respectively. The propulsive inhibitory effect of EEJ at $400 \mathrm{mg} / \mathrm{kg} / \mathrm{bwt}$ was significantly attenuated in the presence of yohimbine $(64.7 \%$ vs. $83.92 \%$ when EEJ [400 mg/kg]) was administered alone.

\section{DISCUSSION}

Diarrhea results from an imbalance between the gastrointestinal absorptive and secretory mechanisms leading to excessive fluid and electrolytes loss in the feces. It is evident enough that diarrhea occurs as a result of increased gastrointestinal motility and secretion as well as decreased intestinal fluid absorption. Therefore, antidiarrheal drugs work by inhibiting either gastrointestinal motility or secretion or both [40]. The present study has demonstrated the potential antidiarrheal properties of ethanolic leaf extract of EEJ in various models of experimental diarrhea, which may be attributable to its dual antisecretory and antimotility activities.

$\mathrm{Na}^{+} / \mathrm{K}^{+}$-ATPase is one of the intestinal key enzymes which plays an important role in the absorption of electrolytes and water in the intestine. Any disruption or inhibition of this enzyme may cause increased intestinal fluid secretion leading to diarrhea $[41,42]$. Castor oil-induced diarrhea is provoked by ricinoleic acid which, in part alters the intestinal mucosa permeability to electrolytes by interfering with the normal activity of $\mathrm{Na}^{+} / \mathrm{K}^{+}$-ATPase resulting in abnormal intestinal absorptive and secretory mechanisms $[43,44]$. In the present study, EEJ significantly inhibited castor oil-induced diarrhea probably by inhibiting intestinal lipase enzymatic activity on castor oil from liberating and releasing ricinoleic acid, an active metabolite of castor oil. Therefore, lack of availability of ricinoleic acid in the intestine indirectly ensured restoration of normal absorptive capacity of the $\mathrm{Na}^{+} / \mathrm{K}^{+}$-ATPase with the concomitant increased intestinal absorption of $\mathrm{Na}^{+}$along with other electrolytes and water. Studies have demonstrated the potential of various herbal extracts to directly enhance the activities of $\mathrm{Na}^{+} / \mathrm{K}^{+}$-ATPase followed by apparent increased intestinal absorptive and decreased secretory capacity [45]. Similar argument may explain the possible direct stimulatory effect of EEJ on the activities of $\mathrm{Na}^{+} / \mathrm{K}^{+}$ATPase which might have led to the increased intestinal absorptive and decreased secretory capacity resulting in protection against castor oil-induced diarrhea. Thus, EEJ may contain phytochemicals with both direct and indirect stimulatory activity on the $\mathrm{Na}^{+} / \mathrm{K}^{+}$-ATPase

Table 1: The effect of EEJ on castor oil-induced intestinal fluid accumulation

\begin{tabular}{llll}
\hline Treatment & VIC $(\mathrm{ml})$ & \% inhibition & WIC (g) \\
\hline Vehicle-treated control & $5.572 \pm 0.301^{++}$ & $5.631 \pm 0.26^{++}$ & \\
EEJ $(100 \mathrm{mg} / \mathrm{kg} / \mathrm{bwt})$ & $4.214 \pm 0.231^{*++}$ & 24.37 & $4.121 \pm 0.287^{*+}$ \\
EEJ $(200 \mathrm{mg} / \mathrm{kg} / \mathrm{bwt})$ & $3.16 \pm 0.147^{*+}$ & 43.29 & $3.052 \pm 0.170^{*+}$ \\
EEJ (400 mg/kg/bwt) & $1.124 \pm 0.221^{* *}$ & 79.83 & $1.216 \pm 0.162^{* *}$ \\
EEJ (400+yohimbine) & $3.02 \pm 0.331^{*+}$ & 45.8 & $3.106 \pm 0.314^{*+}$ \\
EEJ (400+prazosin) & $1.218 \pm 0.18^{* *}$ & 78.14 & $7.303 \pm 0.231^{* *}$ \\
Loperamide & $1.261 \pm 0.32^{* *}$ & 77.37 & $1.432 \pm 0.115^{* *}$ \\
\hline
\end{tabular}

Values are presented as means \pm SEM $(n=6) .{ }^{*} \mathrm{p}<0.05 ;{ }^{* *} \mathrm{p}<0.01$ significantly different compared with negative control group and ${ }^{+} \mathrm{p}<0.05 ;{ }^{++} \mathrm{p}<0.01$ significantly different compared with EEJ ( $400 \mathrm{mg} / \mathrm{kg} / \mathrm{bwt})$. EEJ: Eriobotrya japonica, VIC: Volume of intestinal content in ml, WIC: Weight of intestinal content in g
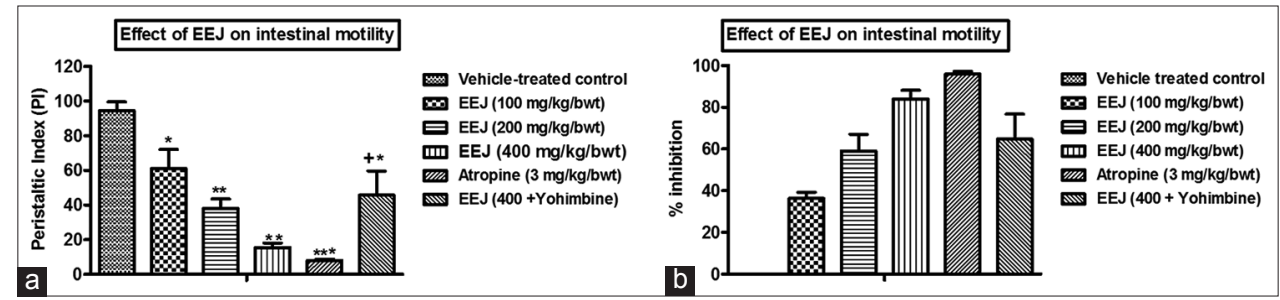

Fig. 2: (a) The effect of Eriobotrya japonica (EEJ) on gastrointestinal motility. Values are presented as means \pm standard errors of the means (SEM) $(\mathrm{n}=6) .{ }^{*} \mathrm{p}<0.05 ;{ }^{* *} \mathrm{p}<0.01$ significantly different compared with negative control group and ${ }^{+} \mathrm{p}<0.05$ significantly different compared with EEJ $(400 \mathrm{mg} / \mathrm{kg} / \mathrm{bwt})$. (b) The inhibitory effect of oral administration of EEJ on gastrointestinal motility. Values are presented as means \pm SEM $(n=6)$ 
on the intestinal mucosa. Therefore, the resultant effect of EEJ due to its indirect and direct activation of $\mathrm{Na}^{+} / \mathrm{K}^{+}$-ATPase on the intestinal mucosa is decreased and increased gastrointestinal secretion and absorption, respectively, leading to marked reduction in fecal output and hence diarrhea.

The other possible mechanistic pathway through which ricinoleic acid triggers diarrhea is by activation of nitric oxide (NO) pathway. Ricinoleic acid is potentially cytotoxic to intestinal epithelial cells and causes increased mucosal permeability which is associated with increased intraluminal fluid accumulation [39]. NO is produced in response to cytotoxins such as ricinoleic acid to intestinal epithelial cells, thereby playing a protective role against cytotoxic-induced intestinal damage. Moreover, studies have demonstrated that pre-treatment of animals with L-NAME, a NO synthase inhibitor attenuates or prevents castor oil-induced diarrhea [46]. Therefore, it would be scientifically reasonable to suggest that certain phytochemicals contained in EEJ might have interfered with the NO pathway resulting in decreased NO synthesis and subsequently, decreased intestinal fluid secretion. On the other hand, considering that EEJ is crude extract, it is obvious that it contains large amount of fiber including protein tannates which make the intestinal mucosa more resistant and decrease secretion with a concomitant enhancement of intestinal absorption.

The enteric nervous system consisting of the myenteric and the submucosal, regulate the activities of the gastrointestinal tract through the secretomotor nerves that release agonists with either direct or indirect effects on epithelial ion transport. Vasoactive intestinal peptide and acetylcholine are the predominant transmitters with direct epithelial secretory effects released by secretomotor nerves [47]. Norepinephrine is the predominant sympathetic neurotransmitter and an agonist in the intestines. Activation of the sympathetic pathway through $\alpha 2$ adrenoceptors on enterocytes in the intestines causes inhibition of motor function of the intestines leading to inhibition of intestinal motility and secretion [48]. The present study has demonstrated the significant protective effect of EEJ against castor oil-induced diarrhea and enteropooling, with the highest dose of $400 \mathrm{mg} / \mathrm{kg} / \mathrm{bwt}$ offering $100 \%$ protection against castor oil-induced diarrhea and $88 \%$ against castor oil induced enteropooling, the effects of which were favorably comparable to that of loperamide, a standard antisecretory drug. The study further showed that the antisecretory activity of EEJ is in part mediated through activation of $\alpha 2$-adrenoceptors and not $\alpha 1$-adrenoceptors. This view was substantiated by comparing the protective effect of EEJ at $400 \mathrm{mg} / \mathrm{kg} /$ bwt in the absence and presence of yohimbine and prazosin against castor oil-induced diarrhea and enteropooling. EEJ at $400 \mathrm{mg} / \mathrm{kg} / \mathrm{bwt}$ significantly reversed the gastrointestinal secretory effect of castor oil in the absence of yohimbine. However, this remarkable antisecretory effect of EEJ at $400 \mathrm{mg} / \mathrm{kg} /$ bwt was successfully antagonised by yohimbine, a selective $\alpha 2$-adrenoceptor blocker. Considering the significant protective effect of this highest dose of EEJ against castor oil-induced diarrhea and enteropooling, and its failure to demonstrate likewise in the presence of yohimbine, it would seem to suggest that the antisecretory activity of EEJ is mediated in part, through activation of $\alpha 2$-adrenoceptors, which resulted in marked inhibition of secretion-inducing neurotransmitters on the secretomotor nerves, thereby enhancing absorption. On the other hand, the protective effects of EEJ at $400 \mathrm{mg} / \mathrm{kg} / \mathrm{bwt}$ against castor oil-induced diarrhea and enteropooling were significantly resistant to antagonism by the $\alpha 1$-adrenoceptors antagonist, prazosin. Therefore, failure of prazosin to significantly reverse the protective effect of highest dose of EEJ against castor oil-induced diarrhea and enteropooling, precludes the involvement of $\alpha 1$-adrenoceptors in the antisecretory activity of EEJ.

The presently described study has further demonstrated the significant inhibitory activity of EEJ against castor oil induced gastrointestinal propulsion. EEJ significantly reduced the PI in a dose-dependent fashion as demonstrated by its ability to reduce the distance traveled by a charcoal meal in the small intestine. The antimotility activity of EEJ would reduce the number and frequency of defecations, thereby preventing diarrhea. On the other hand, the decrease in gastrointestinal propulsion would allow intestinal contents more time of contact with the intestinal mucosa for the absorption which ultimately would reduce fecal output.

It is well established that activation of the sympathetic nervous system enhances fluid and electrolyte absorption through inhibition of gastrointestinal motility. Moreover, strong evidence suggests that activation of $\alpha 2$-adrenoceptors by various agonists mediate inhibition of smooth muscle contraction and hence peristalsis in small intestine probably through inhibition of acetylcholine release from enteric cholinergic nerves $[49,50]$. Thus, in addition, the present study has showed that the antimotility activity of EEJ was in part, mediated through activation of $\alpha 2$-adrenoceptors, since the antimotility activity of EEJ at $400 \mathrm{mg} / \mathrm{kg} / \mathrm{bwt}$ against castor oil-induced gastrointestinal propulsion was significantly attenuated in the presence of yohimbine, a selective $\alpha 2$-adrenoceptor antagonist, probably through inhibition of acetylcholine release from enteric cholinergic nerves.

The present findings on the effect of EEJ on gastrointestinal motility are partly in agreement with Matimba et al. [51], who reported the antispasmolytic activity of ethanolic leaf extract of EEJ on isolated rabbit ileum in vitro and this relaxant effect was suggested to be mediated through blockade of histamine and muscarinic receptors.

Use of medicinal plants as therapies for various diseases has over years gained popularity partly due to the common belief that they are safe and have fewer side effects. However, many plant-based products may be toxic and have significant adverse effects on human beings. It is, therefore, imperative that potential toxicity of medicinal plants be determined before consumption of the plant materials. The present study carried out the toxicity study of EEJ using a simple and rapid brine shrimp lethality assay. This assay is widely employed in toxicological tests involving screening of large numbers of medicinal plant extracts for drug discovery $[52,53]$ and as a matter of fact, some studies have reported significant correlation between the $\mathrm{LC}_{50}$ value obtained with brine shrimp lethality assay and the $\mathrm{LD}_{50}$ value obtained from the acute oral toxicity assay done in mice [54]. Therefore, this assay could conveniently and potentially replace other biological models such as in vivo assays involving the use of live laboratory animals which are constantly facing ethical issues. The study has demonstrated that $\mathrm{EEJ}$ is not toxic as determined by its higher $\mathrm{LD}_{50}$ value of $1225 \mu \mathrm{g} / \mathrm{ml}$, probably suggesting safety of EEJ for human consumption. However, the fact that EEJ at $400 \mathrm{mg} / \mathrm{kg} / \mathrm{bwt}$ completely abolished defecation during the entire experimental duration just as loperamide did, it may seem to appear that, higher doses of EEJ may induce constipation, which is yet another gastrointestinal problem affecting many people worldwide [55]. Thus, it may be advisable that consumption of the materials derived from this plant be done with some degree of cautiousness especially at higher doses.

\section{CONCLUSION}

The present study has demonstrated the potential antidiarrheal properties of ethanolic leaf extract of EEJ using various models of experimental diarrhea. The extract seems to mediate its antidiarrheal activity in part, through activation of $\alpha 2$-adrenoceptors. The extract may also, on the other hand, mediate its effect through modulation of the $\mathrm{Na}^{+} / \mathrm{K}^{+}$-ATPase and NO pathways. Therefore, extracts from EEJ, if properly and adequately standardized, may serve as a safe and costeffective, potential therapeutic agent, with antidiarrheal properties. The study has shed more light on the scientific basis for the use of $\mathrm{EEJ}$ in the treatment of diarrhea and other associated gastrointestinal disorders by some communities of the Eastern Cape Province of the Republic of South Africa.

\section{Limitations and recommendations}

The present study has established only one mechanistic pathway through which EEJ mediates its antidiarrheal effect, yet the other mentioned mechanisms are mainly based on speculations. Therefore, further investigations are warranted to establish other mechanistic pathways, through which, EEJ exerts its antidiarrheal actions. 
Furthermore, the study did not carry out a phytochemical analysis of the extract as such it is imperative that future studies should focus on identification, isolation, and screening of the active compounds for their antidiarrheal properties.

\section{ACKNOWLEDGMENTS}

The authors are grateful for the financial support provided by the office of the Directorate of Research, Walter Sisulu University, Republic of South Africa.

\section{AUTHOR'S CONTRIBUTIONS}

The study was initiated and designed by Dr Kamadyaapa while all authors equally contributed to both experimental work and preparation of the manuscript.

\section{CONFLICT OF INTEREST}

The authors declare that they have no conflicts of interest.

\section{REFERENCES}

1. Weber TK, Polanco I. Gastrointestinal microbiota and some children diseases: A review. Gastroenterol Res Pract 2012;2012:872716.

2. UNICEF W. Why Children are Still Dying and What can be Done. WHO: Diarhhoea; 2009.

3. Maiti A, Dewanjee S, Mandal SC. In vivo evaluation of antidiarrhoeal activity of the seed of Swietenia macrophylla King (Meliaceae). Trop J Pharm Res 2007;6:711-6.

4. Pratap B, Kumar R, Tiwari D, Yadav S, Singh S. Evaluation of antidiarrhoeal property of the hydroalcoholic extract of roots of Calotropis gigantea $\mathrm{R}$. Br. on Caster-induced diarrhoea in rats. Der Pharm Lett 2010;2:309-14.

5. Bhargav A, Hemamalini K, Uma Vasireddy SS, Vijusha ML. Antidiarrheal activity of methanolic extract of leaves of Solanum pubescens Willd and Gymnosporia emerginata. Asian J Pharm Clin Res 2012;5:226-7

6. Chola L, Michalow J, Tugendhaft A, Hofman K. Reducing diarrhoea deaths in south Africa: Costs and effects of scaling up essential interventions to prevent and treat diarrhoea in under-five children. BMC Public Health 2015;15:394

7. Mohammed S, Tamiru D. The burden of diarrheal diseases among children under five years of age in Arba Minch district, Southern Ethiopia, and associated risk factors: A Cross-sectional study. Int Sch Res Notices 2014;2014:654901.

8. Barlow M. The Global Water Crisis and the Commodification of the World's Water Supply. In International Forum on Globalization 2010.

9. Kahinda JM, Taigbenu AE, Boroto JR. Domestic rainwater harvesting to improve water supply in rural South Africa. Phys Chem Earth 2007;32:1050-7.

10. Hutton G, Haller L, Bartram J. Global cost-benefit analysis of water supply and sanitation interventions. J Water Health 2007;5:481-502.

11. South African Human Rights Commission. Report on the right to access sufficient water and decent sanitation in South Africa: 2014. Braamfontein, South Africa. S Afr Human Rights Commission 2014;2:20-3

12. Appidi JR, Grierson DS, Afolayan AJ. Ethnobotanical study of plants used for the treatment of diarrhoea in the eastern cape, South Africa. Pak J Biol Sci 2008;11:1961-3.

13. Brijesh S, Daswani PG, Tetali P, Rojatkar SR, Antia NH, Birdi TJ, et al. Studies on Pongamia pinnata (L.) pierre leaves: Understanding the mechanism(s) of action in infectious diarrhea. J Zhejiang Univ Sci B 2006; 7:665-74

14. Kotloff KL, Nataro JP, Blackwelder WC, Nasrin D, Farag TH, Panchalingam $\mathrm{S}$, et al. Burden and aetiology of diarrhoeal disease in infants and young children in developing countries (the global enteric multicenter study, GEMS): A prospective, case-control study. Lancet 2013;382:209-22.

15. Walker CLF, Rudan I, Liu L, Nair H, Theodoratou E, Bhutta ZA, et al. Global burden of childhood pneumonia and diarrhoea. Lancet 2013;381:1405-16

16. Kumar R, Sharma RJ, Bairwa K, Roy RK, Kumar A. Pharmacological review on natural antidiarrhoel agents. Der Pharm Chem 2010;2:66-93.

17. Statistics South Africa: Levels and Trends of Morbidity and Mortality Among Children Aged Under Five Years In South Africa, 2006-2010.
Pretoria, South Africa: Statistics South Africa; 2012.

18. Akuodor GC, Muazzam I, Usman-Idris M, Megwas UA, Akpan JL, Chilaka KC, et al. Evaluation of the antidiarrheal activity of methanol leaf extract of Bombax buonopozense in rats. Ibnosina J Med BS 2011;3:15-20

19. Formiga RO, Quirino ZGM, Diniz MFFM, Marinho AF, Tavares JF, Batista LM, et al. Maytenus erythroxylon reissek (Celastraceae) ethanol extract presents antidiarrheal activity via antimotility and antisecretory mechanisms. World J Gastroenterol 2017;23:4381-9.

20. Tadesse WT, Hailu AE, Gurmu AE, Mechesso AF. Experimental assessment of antidiarrheal and antisecretory activity of $80 \%$ methanolic leaf extract of Zehneria scabra in mice. BMC Complement Altern Med 2014;14:460

21. Nwabunike IA, Okoli CO, Ezeugwu P, Ezike AC, Onyeto CA, Mbaoji FN, et al. Antidiarrheal potentials of Schwenckia americana L. (Solanaceae): A comparative study of the aerial part and root extracts. Int J Pharm Pharm Sci 2018;10:195-201.

22. Bisi-Johnson MA, Obi CL, Kambizi L, Nkomo M. A survey of indigenous herbal diarrhoeal remedies of OR Tambo district, Eastern Cape Province, South Africa. Afr J Biotechnol 2010;9:1245-54

23. Kim HS. Do not put too much value on conventional medicines. J Ethnopharmacol 2005;100:37-9.

24. Sanger GJ, Alpers DH. Development of drugs for gastrointestinal motor disorders: Translating science to clinical need. Neurogastroenterol Motil 2008;20:177-84.

25. Beyi L, Aziz M, Makrane H, Karim A, Bnouham M, Ziyyat A. Antidiarrheal activity of thymus Algeriensis boiss and reut aqueous extract on rats and mice. Int J Pharm Pharm Sci 2015;7:292-4

26. Nwidu LL, Essien GE, Nwafor PA, Vilegas W. Antidiarrheal mechanism of Carpolobia lutea leaf fractions in rats. Pharm Biol 2011;49:1249-56.

27. Palombo EA. Phytochemicals from traditional medicinal plants used in the treatment of diarrhoea: Modes of action and effects on intestinal function. Phytother Res 2006;20:717-24.

28. Sakuramata Y, Oe H, Kusano S, Aki O. Effects of combination of Caiapo ${ }^{\circledR}$ with other plant-derived substance on anti-diabetic efficacy in KK-Ay mice. BioFactors 2004;22:149-52.

29. Zong W, Zhao G. Corosolic acid isolation from the leaves of Eriobotrta japonica showing the effects on carbohydrate metabolism and differentiation of 3T3-L1 adipocytes. Asia Pac J Clin Nutr 2007;16 Suppl 1:346-52.

30. Liu Y, Zhang W, Xu C, Li X. Biological activities of extracts from loquat (Eriobotrya japonica lindl.): A Review. Int J Mol Sci 2016;17: pii: E1983

31. Tanaka K, Nishizono S, Makino N, Tamaru S, Terai O, Ikeda I, et al. Hypoglycemic activity of Eriobotrya japonica seeds in Type 2 diabetic rats and mice. Biosci Biotechnol Biochem 2008;72:686-93.

32. Li WL, Wu JL, Ren BR, Chen J, Lu CG. Pharmacological studies on anti-hyperglycemic effect of folium Eriobotryae. Am J Chin Med 2007;35:705-11.

33. Nguta JM, Mbaria JM, Gakuya DW, Gathumbi PK, Kabasa JD, Kiama SG. Evaluation of acute toxicity of crude plant extracts from Kenyan biodiversity using brine shrimp, Artemia salina L.(Artemiidae). Open Conf Proc J 2012;3:30-4

34. Molina-Salinas GM, Said-Fernández S. A modified microplate cytotoxicity assay with brine shrimp larvae (Artemia salina). Pharmacologyonline 2006;(3): 633-8.

35. Bastos ML, Lima MR, Conserva LM, Andrade VS, Rocha EM, Lemos RP. Studies on the antimicrobial activity and brine shrimp toxicity of Zeyheria tuberculosa (Vell.) Bur.(Bignoniaceae) extracts and their main constituents. Ann Clin Microbiol Antimicrob 2009;8:16.

36. Zavala-Mendoza D, Alarcon-Aguilar FJ, Pérez-Gutierrez S, EscobarVillanueva MC, Zavala-Sánchez MA. Composition and antidiarrheal activity of Bidens odorata cav. Evid Based Complement Alternat Med 2013;2013:170290.

37. Umukoro S, Ashorobi RB. Effect of Aframomum melegueta. Seed extract on castor oil-induced diarrhea. Pharm Biol 2005;43:330-3.

38. Marona HR, Lucchesi MB. Protocol to refine intestinal motility test in mice. Lab Anim 2004;38:257-60.

39. Degu A, Engidawork E, Shibeshi W. Evaluation of the anti-diarrheal activity of the leaf extract of croton Macrostachyus hocsht. Ex del. (Euphorbiaceae) in mice model. BMC Complement Altern Med 2016;16:379.

40. Otimenyin S, Uzochukwu DC. Spasmolytic and anti-diarrhea effects of the bark of Erythrina senegalensis and root of Kigelia africana. Asian J Pharm Clin Res 2010;3:6-8.

41. Yakubu MT, Nurudeen QO, Salimon SS, Yakubu MO, Jimoh RO, Nafiu MO, et al. Antidiarrhoeal activity of Musa paradisiaca sap in 
wistar rats. Evid Based Complement Alternat Med 2015;2015:683726.

42. Babitha S, Deepu HG, Nageena TA. Antimotility and antisecretory related antidiarrhoeal activity of the Abelmoschus moschatus medik in experimental animal models. Int J Pharm Pharm Sci 2018;10:108-11.

43. Sairam K, Hemalatha S, Kumar A, Srinivasan T, Ganesh J, Shankar M, et al. Evaluation of anti-diarrhoeal activity in seed extracts of Mangifera indica. J Ethnopharmacol 2003;84:11-5.

44. Rahman MK, Chowdhury MA, Islam MT, Chowdhury MA, Uddin ME, Sumi CD, et al. Evaluation of antidiarrheal activity of methanolic extract of Maranta arundinacea Linn. Leaves. Adv Pharmacol Sci 2015;2015:257057.

45. Sahoo HB, Sagar R, Kumar A, Bhaiji A, Bhattamishra SK. Antidiarrhoeal investigation of Apium leptophyllum (Pers.) by modulation of $\mathrm{Na}+\mathrm{K}+$ ATPase, nitrous oxide and intestinal transit in rats. Biomed J 2016;39:376-81.

46. Shamkuwar, P. Role of potassium channels, nitric oxide pathway and adrenergic receptors in antidiarrhoeal effect of mebarid. Asian J Pharm Clin Res 2013;6:295-6.

47. Field M. Intestinal ion transport and the pathophysiology of diarrhea. J Clin Invest 2003;111:931-43.

48. Damabi NM, Moazedi AA, Seyyednejad SM. The role of $\alpha$-and $\beta$-adrenergic receptors in the spasmolytic effects on rat ileum of Petroselinum crispum Latifolum (parsley). Asian Pac J Trop Med
2010;3:866-70.

49. Nasser Y, Ho W, Sharkey KA. Distribution of adrenergic receptors in the enteric nervous system of the guinea pig, mouse, and rat. J Comp Neurol 2006:495:529-53.

50. Stebbing M, Johnson P, Vremec M, Bornstein J. Role of alpha(2)adrenoceptors in the sympathetic inhibition of motility reflexes of guinea-pig ileum. J Physiol 2001;534:465-78.

51. Matimba GR, Gadaga L, Mawoza T, Mubika B, Chitindingu K, Taderera T. Mechanistic studies of myorelaxant effects of ethanolic leaf extract of Eriobotyra japonica on isolated rabbit ileum. Int J Res Dev Pharm Life Sci 2015;4:1679-85.

52. Hamidi M, Jovanova B, Panovska T. Toxicological evaluation of the plant products using brine shrimp (Artemia salina L.) model. Macedonian Pharm Bull 2014;60:9-18.

53. Naidu JR, Ismail R, Sasidharan S. Acute oral toxicity and brine shrimp lethality of methanol extract of Mentha spicata L (Lamiaceae). Trop J Pharm Res 2014;13:101-7.

54. Arslanyolu M, Erdemgil FZ. Evaluation of the antibacterial activity and toxicity of isolated arctiin from the seeds of Centaurea sclerolepis. Ankara Ecz Fak Derg 2006;35:103-9.

55. Chang JY, Locke GR $3^{\text {rd }}$, McNally MA, Halder SL, Schleck CD, Zinsmeister AR, et al. Impact of functional gastrointestinal disorders on survival in the community. Am J Gastroenterol 2010;105:822-32. 